\title{
Physiochemical Properties of Soil in Selected Sites of the Lake Chilwa Basin after 5 years of Conservation Agriculture Practice
}

\author{
Willie Cliffie John Sagona*, Owen Kachala, Sophie Matete, Herbert Jenya \\ Forestry Research Institute of Malawi (FRIM), Malawi
}

Copyright $(2016$ by authors, all rights reserved. Authors agree that this article remains permanently open access under the terms of the Creative Commons Attribution License 4.0 International License.

\begin{abstract}
Conservation Agriculture (CA) has been implemented in the Lake Chilwa basin for over 5 years in response to the rising interest in exploring the potential of $\mathrm{CA}$ as one of the sustainable agricultural production technologies in Malawi. Soil physiochemical characterization was carried out in some selected Extension Planning Areas (EPAs) before CA implementation. The aim was to lay basis for future monitoring of the physiochemical soil changes that the $\mathrm{CA}$ intervention might bring. Collected soil samples were analyzed in a laboratory using standard analysis procedures. Soils were found to be generally nitrogen deficient during baseline study. The results were attributed to unsustainable land use practices that required interventions such as CA practice. The physiochemical status of the soil was once again reviewed after 5years of CA practice and current results show some improvements in some soil properties and a decline in others. Recorded changes continue to show significant differences $(\mathrm{P} \leq 0.05)$ across the EPAs under study but no significant variation $(\mathrm{P} \geq 0.05)$ along the soil depth $(0-30 \mathrm{~cm})$. The negative decline in soil status is attributed to nutrient loss through heavy leaching under waterlogged conditions experienced in the basin prior to the second soil review.
\end{abstract}

Keywords Soil, Physical, Chemical, Conservation Agriculture

\section{Introduction}

The question of providing enough food and better nutrition to the world's poorest people, the majority of whom are in the tropics, is a very big challenge today[1]. There is great concern on adequate food supply especially when viewed against very meager crop yields and ever-increasing cost of labour and farm inputs. Malawi is no exemption because a better part of Malawi's population lives in rural areas and make out a living based on unimproved traditional agricultural production systems in areas that are largely marginal. Due to increasing population pressure, many of these fragile ecosystems have suffered rapid degradation; soil fertility loss resulting in significant productivity decrease. Consequently, food supplies are dwindling, and hunger and malnutrition are rampant.

Agriculture is the mainstay of Malawi's economy and it contributes about $33.6 \%$ to the economic growth [2]. In the 2004 Malawi Economic Growth Strategy, it accounted for $39 \%$ of Gross Domestic Product (GDP), $85 \%$ of the labour force and $83 \%$ of foreign exchange earnings. Reference [3] contends that $95 \%$ of the rural population depends on agriculture for both food and income. As the land progressively degrades, the struggle to survive for poor and vulnerable rural households is becoming even harder.

Sustainable use of soil resources remains a critical determinant of agricultural productivity in Malawi especially among smallholder farmers who prioritize maize over other food and cash crops. Various studies have reported declining levels of soil productivity that pose serious food security concerns [4]. Apart from land degradation, smallholder agriculture is being threatened by climate change resulting in unstable yields.

One of the areas that have been adversely affected by land degradation is the Lake Chilwa basin. Presently, most lives and livelihoods in the basin are under threat. Limiting nitrogen availability, soil erosion and rapid population growth among other problems hinder soil productivity in the Lake Chilwa basin and climate change and variability impacts have exacerbated the situation. The basin, thus, currently faces multiple severe challenges associated with land degradation which have resulted into fast and steady deprivation of people's livelihoods most of whom are poor. Climate change, in particular, is believed to have a great impact on soils and agriculture production.

Introduction of Conservation Agriculture (CA) in the basin has been considered as the most promising 
sustainable land use system not only to arrest the detrimental trends of poor land use practices but also to provide a stable food supply to the affected people in the face of climate change, and in some cases, to reclaim degraded areas. Thus, before CA intervention was undertaken, an evaluation of soil physical and chemical characteristics was done in order to establish the soil fertility status of some selected EPAs within the Lake Chilwa Basin hotspots and another soil study followed 5 years after CA implementation to document any resultant changes in physiochemical condition of the soil.

Forestry Research Institute of Malawi (FRIM) with support from Lake Chilwa Basin Climate Change Adaptation Program (LCBCCAP) conducted a baseline survey to build basis for any future changes in soil chemical and physical properties. This report reviews findings from soil status study that was conducted in the three Lake Chilwa basin districts of Zomba, Machinga and Phalombe before and after CA implementation in the selected Extension Planning Areas (EPAs).

\section{Materials and Methods}

The Lake Chilwa basin is located in the southern part of Malawi. Topography is made up of uplands and lowlands. Variability in terms of parent material and soils is high. The uplands have deep, well-drained sandy soils derived from the gneiss while the lowlands have very deep soils with variable drainage and texture in fluvial, colluvial and lacustrine deposits [5]. The Lake Chilwa basin was formed as a result of tectonic forces and has progressively been filled with sand, silt and various debris through denudation processes of the down-warped Shire Highlands Miocene peneplain. Within the basin, Phalombe has 73, 880 hectares, Machinga has about 112,000 hectares and Zomba has 185,174 hectares of arable land. The eastern side of the lake and the river mouths of some rivers are made up of sandy soils $[6 ; 5]$.

\subsection{Soil Samples Collection}

Soil samples were collected before CA implementation and 5 years after $\mathrm{CA}$ practice in the demonstration fields of the three districts of the Lake Chilwa Basin namely; Phalombe (Kasongo, Tamani and Naminjiwa EPAs), Zomba (Ngwelero and Malosa EPAs) and Machinga (Nsanama and Domasi EPAs). Kasongo, Tamani, Naminjiwa, Malosa and Nsanama EPAs had 30 fields each located in three clusters represented by 10 fields while Ngwelero and Domasi EPAs had 45 fields each located in three clusters represented by 15 fields each. Each field had land area of 0.2 hectare, thus in total Phalombe had 18 hectares, Zomba had 15 hectares and Machinga had 15 hectares under observation. Three composite samples were collected from each field at a depth of $0-10 \mathrm{~cm}, 11-20 \mathrm{~cm}$ and $21-30 \mathrm{~cm}$ and 720 soil samples were collected from selected 240 representative fields on each occasion. Within a cluster, soil sample collection points (from one field to another) were at a distance ranging between 250 and 350 metres. A cluster represented a particular landscape configuration and these were categorized according to slope (steep, moderate and gentle). GPS coordinates were used to maintain soil sample collecting points. These sites are located in the designated basin hotspots which are prone to drought, with variable mean annual rainfall range between $800-1,200 \mathrm{~mm}$. In these areas poor soil quality is one of the main causes of pitiable crop performance at farm level and the areas are generally said to be of low productivity.

\subsection{Laboratory Soil Analysis}

The soil samples were analyzed in a laboratory for physical and chemical properties using standard analysis procedures [7] to determine soil texture, soil bulky density, soil $\mathrm{pH}$, soil organic matter, soil carbon, soil nitrogen, available potassium and phosphorus.

Soil Organic Matter (SOM) is organic materials found in soils irrespective of origin or state of decomposition. Since SOM consists of $\mathrm{C}, \mathrm{H}, \mathrm{O}, \mathrm{N}, \mathrm{P}$, and $\mathrm{S}$ it is difficult to actually measure the SOM content and laboratory analytical method determined the soil organic carbon content (which can be readily measured) and estimated SOM through a conversion factor.

\subsection{Statistical Data Analysis}

Soil organic matter, soil carbon, soil $\mathrm{pH}$, soil nitrogen, available potassium and phosphorus recorded were tested for normality and homogeneity with Kolmogorov-Smirnov D using Genstat 4 analytical software. After the two criteria were met, the data were subjected to analysis of variance (ANOVA) using the same software. Means and ranges were used to summarize the data for presentation.

\section{Results}

\subsection{Soil Physical Analysis}

\subsubsection{Soil Texture}

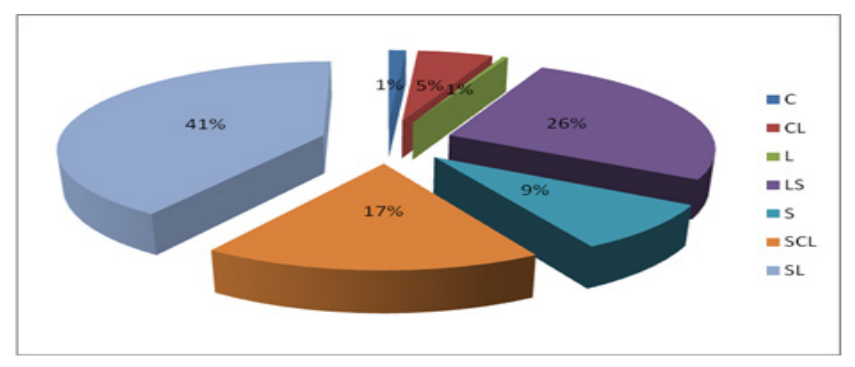

Figure 1. Soil texture distribution in the Lake Chilwa basin

Seven specific textural classes (Figure 1) were observed in the three Lake Chilwa basin districts of Zomba Machinga 
and Phalombe and these are; clay, clay loam, loam, loamy sand, sand, sandy clay loam and sandy loam soils. The baseline study generally observed that Lake Chilwa basin is dominated by sandy loam soils (41\%), loamy sand soils (26\%) and Sandy clay loam soils (17\%). Other textural classes such as clay and loam soils are the least prevalent in the basin.

\subsubsection{Soil Bulk Density}

The overall mean bulk density from 0 to $30 \mathrm{~cm}$ soil depth during baseline study was $1.50 \mathrm{gcm}^{-3}$, and it ranged from $1.10 \mathrm{gcm}^{-3}$ to $1.60 \mathrm{gcm}^{-3}$. Malosa EPA had the highest overall mean bulk density $\left(1.60 \mathrm{gcm}^{-3}\right)$ while Ngwelero EPA had the least mean bulk density $\left(1.45 \mathrm{gcm}^{-3}\right)$. It was observed during baseline that sand soils had high bulk density $\left(1.60 \mathrm{gcm}^{-3}\right)$ although within the tolerable range. Statistical analysis of the results showed that the mean soil bulk density did not vary significantly with soil depth $(\mathrm{P} \geq 0.05)$. However, the results showed that they varied significantly $(\mathrm{P} \leq 0.05)$ across the EPAs.

After implementing CA for 5 years, overall bulk density mean from 0 to $30 \mathrm{~cm}$ soil depth had come down to 1.41 $\mathrm{gcm}^{-3}$ and ranged from $1.1 \mathrm{gcm}^{-3}$ to $1.5 \mathrm{gcm}^{-3}$. The results still show that bulk density did not vary with depth in all EPAs under study. However, Malosa EPA recorded the highest mean bulk density (from $1.6 \mathrm{gcm}^{-3}$ to $1.5 \mathrm{gcm}^{-3}$ ) while Ngwelero EPA maintained the least mean bulk density but this time shifted from 1.45 to $1.1 \mathrm{gcm}^{-3}$ after CA implementation which is ideal for plant growth. The results show that mean bulk density was not significantly different $(\mathrm{P} \geq 0.05)$ from 0 to $30 \mathrm{~cm}$ depth but varied significantly across EPAs $(\mathrm{P} \leq 0.05)$.
Table 1. Ideal Bulk Densities for Specific Soil Textural Classes

\begin{tabular}{|c|c|c|}
\hline $\begin{array}{c}\text { Soil } \\
\text { Texture }\end{array}$ & $\begin{array}{c}\text { Ideal bulk densities for } \\
\text { plant growth }\left(\mathrm{g} / \mathrm{cm}^{3}\right)\end{array}$ & $\begin{array}{c}\text { Bulk densities that restrict } \\
\text { root growth }\left(\mathrm{g} / \mathrm{cm}^{3}\right)\end{array}$ \\
\hline Sandy & $<1.60$ & $>1.80$ \\
\hline Silty & $<1.40$ & $>1.65$ \\
\hline Clayey & $<1.10$ & $>1.47$ \\
\hline
\end{tabular}

Source: (http://www.soilsurvey.org)

\subsection{Soil Chemical Properties}

\subsubsection{Soil $\mathrm{pH}$}

Baseline results showed that the soils in the study area ranged from slightly acidic to near neutral with mean $\mathrm{pH}$ ranging between 5.5 and 6.0. Nsanama EPA recorded highest mean $\mathrm{pH}$ (6.0) whilst Ngwelero had the lowest mean $\mathrm{pH}$ (5.5). Generally, the soils under observation fell within the acceptable soil $\mathrm{pH}$ range but did not show any significant difference $(\mathrm{P} \geq 0.05)$ as we dig from 0 to $30 \mathrm{~cm}$. However, the results showed significant differences $(\mathrm{P} \leq 0.05)$ across EPAs.

Latest results after 5 years of CA implementation have shown changes in $\mathrm{pH}$ levels of all the seven (7) EPAs under study. The observed overall mean soil $\mathrm{pH}$ is 5.0 having a range of between 4.50 and 5.33 which is slightly acidic. Nsanama EPA again recorded the highest soil $\mathrm{pH}$ at 5.33 after 5 years of CA implementation from 6.0 which was recorded during baseline; Tamani EPA has recorded the lowest soil $\mathrm{pH}$ at 4.50 after years of CA practice, displacing Ngwelero EPA which formerly had the lowest at 5.5 at baseline. Except for Kasongo EPA, SOM is inversely proportional to soil $\mathrm{pH}$ status in all EPAs under study (Figure 3). The results show significant differences $(\mathrm{P} \leq 0.05)$ across the EPAs but show no significant variation $(\mathrm{P} \geq 0.05)$ from 0 to $30 \mathrm{~cm}$ depth.

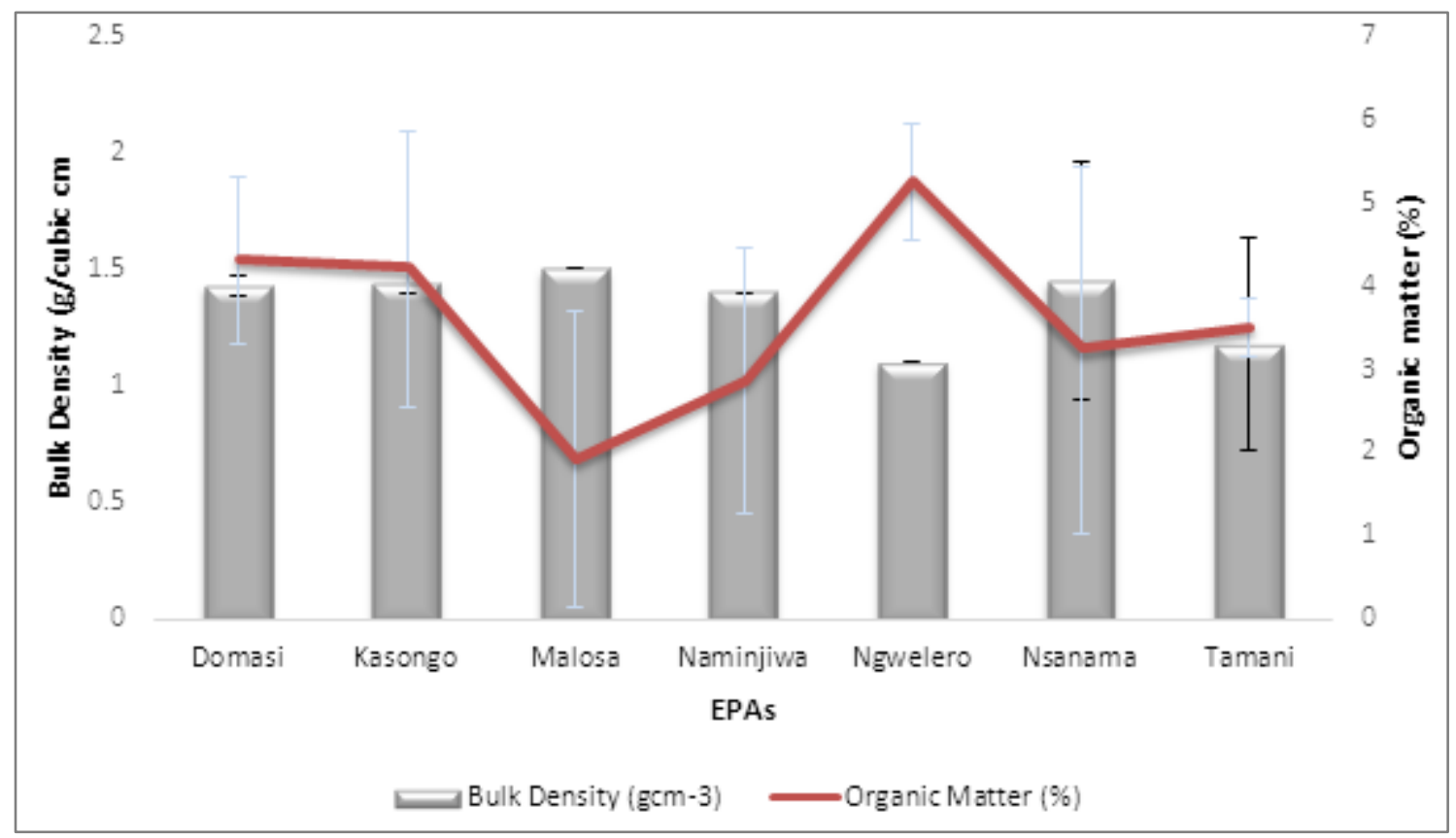

Figure 2. Soil bulk density behaviour in relation to available SOM in the study area 


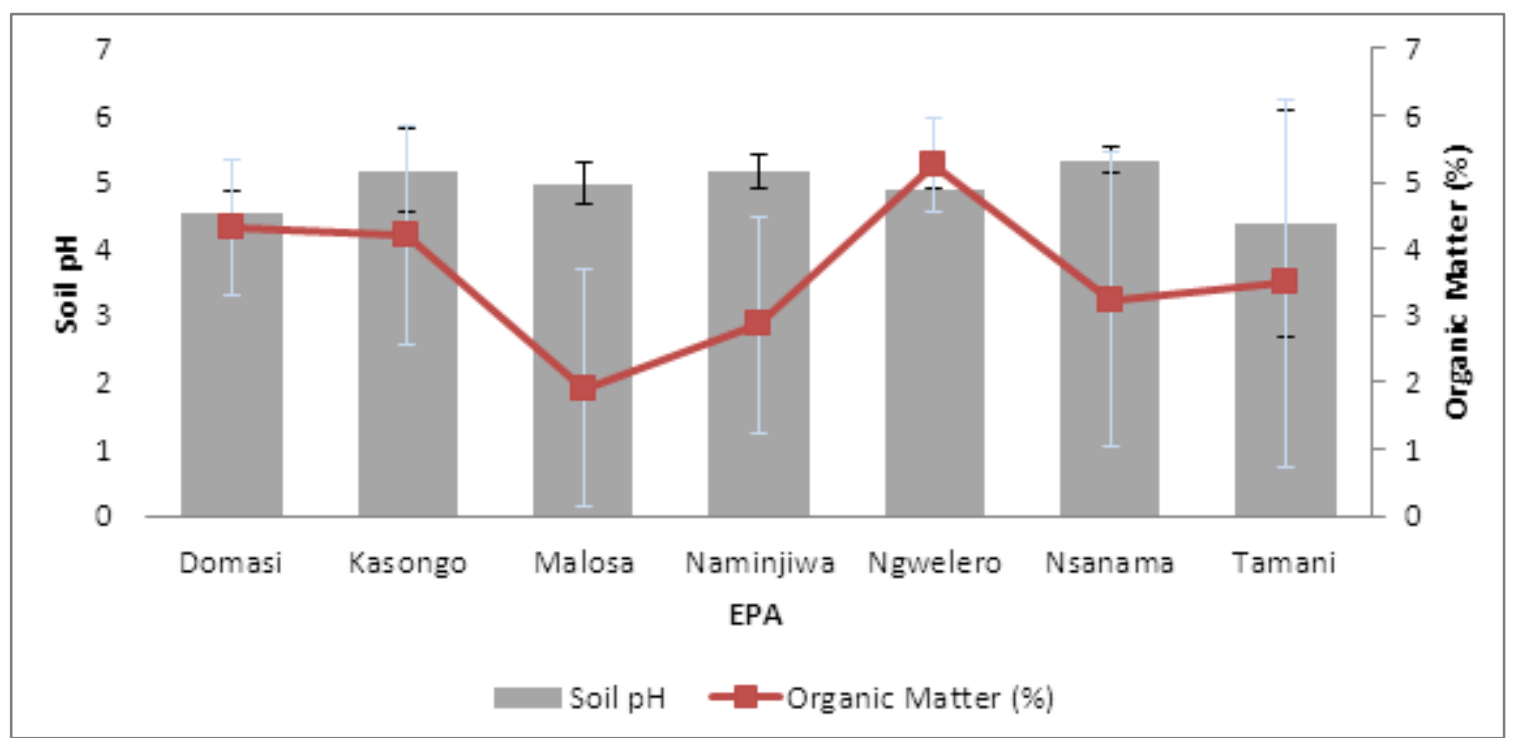

Figure 3. Observed soil $\mathrm{pH}$ status in relation to SOM in the study area

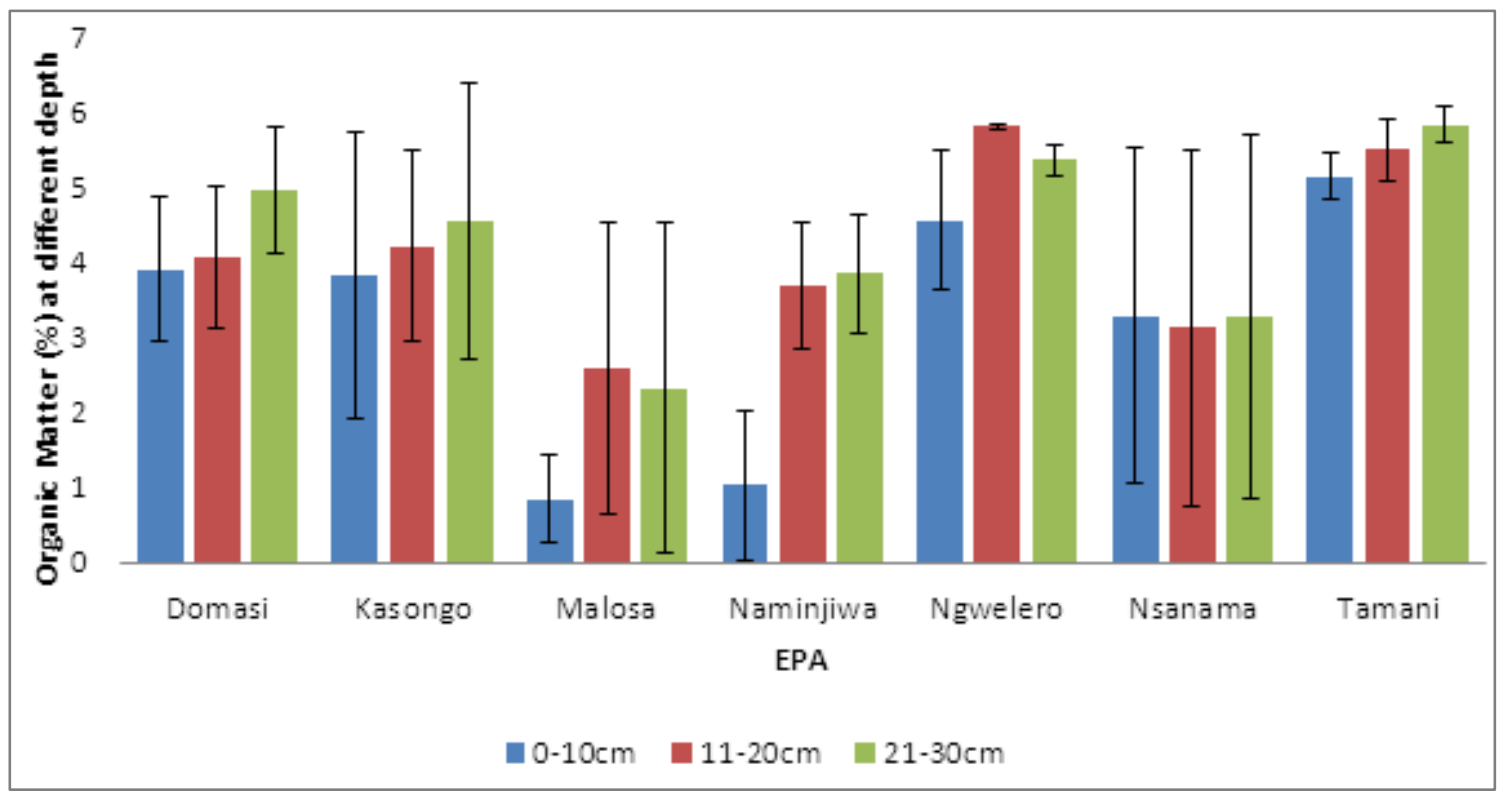

Figure 4. Soil organic matter distribution at different depths (0 to $30 \mathrm{~cm})$ of the soil profile

\subsubsection{Soil Organic Matter}

Soil organic matter (SOM) content during baseline study fell within the normal range for agro-ecozones of Malawi (2 to $6 \%$ ), except for Ngwelero EPA which was the least (1.21\%). The results show that Naminjiwa EPA recorded the highest mean SOM content at 3.32\%. Although SOM concentration varied with depth, there was no clear pattern of variation. Distribution of SOM from 0 to $30 \mathrm{~cm}$ depth along the profile had no significant variation $(\mathrm{P} \geq 0.05)$ yet the results varied significantly across the EPA $(\mathrm{P} \leq 0.05)$.

A review of SOM after 5 years of CA implementation revealed a range of between 1.91 and $5.50 \%$. Tamani EPA recorded the highest SOM (5.50\%) an increase from 2.37 which was recorded at baseline while Malosa EPA recorded the lowest SOM (1.91\%) an increase from 1.52 which was recorded at baseline. Ngwelero EPA which formerly recorded lowest SOM (1.21\%) had recorded second highest $\mathrm{SOM}$ at $5.25 \%$. The results further show that Ngwelero, Malosa, Kasongo, Tamani and Nsanama EPAs gained in SOM over the 5 years of CA practice while Domasi $(4.64 \%$ to $4.31 \%$ ) and Naminjiwa (3.30\% to $2.86 \%$ ) had negligible reduction in SOM status of $0.33 \%$ and $0.44 \%$ respectively after 5 years of CA implementation. The results show that there was no significant difference $(\mathrm{P} \geq 0.05)$ in the recorded $\mathrm{SOM}$ from 0 to $30 \mathrm{~cm}$ depth but differed significantly $(\mathrm{P} \leq 0.05)$ across all the EPAs. Thus, there is no clear pattern of SOM distribution from 0 to $30 \mathrm{~cm}$ depth (Figure 4 ) in the EPAs under study.

\subsubsection{Soil carbon}

Soil carbon is the main constituent of SOM. Results during baseline study showed that Naminjiwa EPA had the 
highest mean soil carbon percentage (1.92\%) as compared to other sites. This augured well with the recorded high mean SOM then. It was also noted that carbon content variation with depth was negligible and did not show a clear pattern. Statistical analysis showed that there was no significant difference $(\mathrm{P} \geq 0.05)$ as we move from 0 to $30 \mathrm{~cm}$ in the soil profile but the results showed significant differences $(\mathrm{P} \leq 0.05)$ across the EPAs.

Soil carbon observed after 5 years of CA implementation show an overall mean of $2.16 \%$ with a range of between $1.11 \%$ and $3.21 \%$ across the EPAs under study. Ngwelero EPA recorded the highest soil carbon mean (3.21\%) while Malosa had the least mean (1.11\%). Naminjiwa EPA which at baseline had recorded the highest mean (1.92\%) had declined to $1.66 \%$ after 5years of CA implementation. The results show significant differences $(\mathrm{P} \leq 0.05)$ across EPAs but do not significantly vary $(\mathrm{P} \geq 0.05)$ from 0 to $30 \mathrm{~cm}$ depth. The results agree with the fact that carbon is a key ingredient of soil organic matter because any increase in SOM is directly proportional to an increase in soil carbon (Figure 5).

Along the soil profile ( 0 to $30 \mathrm{~cm}$ ), none of the EPAs had abundant soil carbon in the top soil of 0 to $10 \mathrm{~cm}$ as normally expected. Malosa, Ngwelero and Nsanama had more soil carbon mean within 11 to $20 \mathrm{~cm}$ depth at 1.50 , 3.37 and $1.91 \%$ respectively. Domasi (2.88\%), Kasongo (2.64\%), Naminjiwa (2.23\%) and Tamani (3.39\%) had more soil carbon within the 21 to $30 \mathrm{~cm}$ depth of the soil profile (Figure 6).

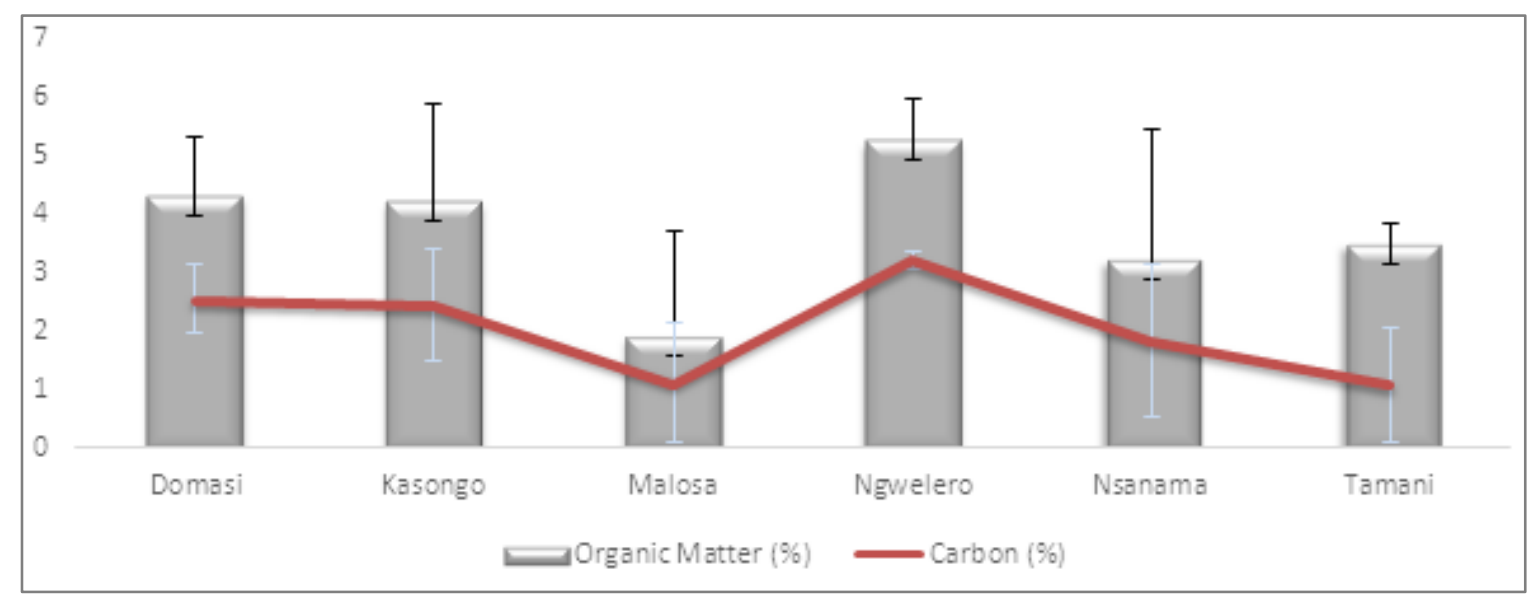

Figure 5. Relationship showing soil carbon as a key ingredient to soil organic matter

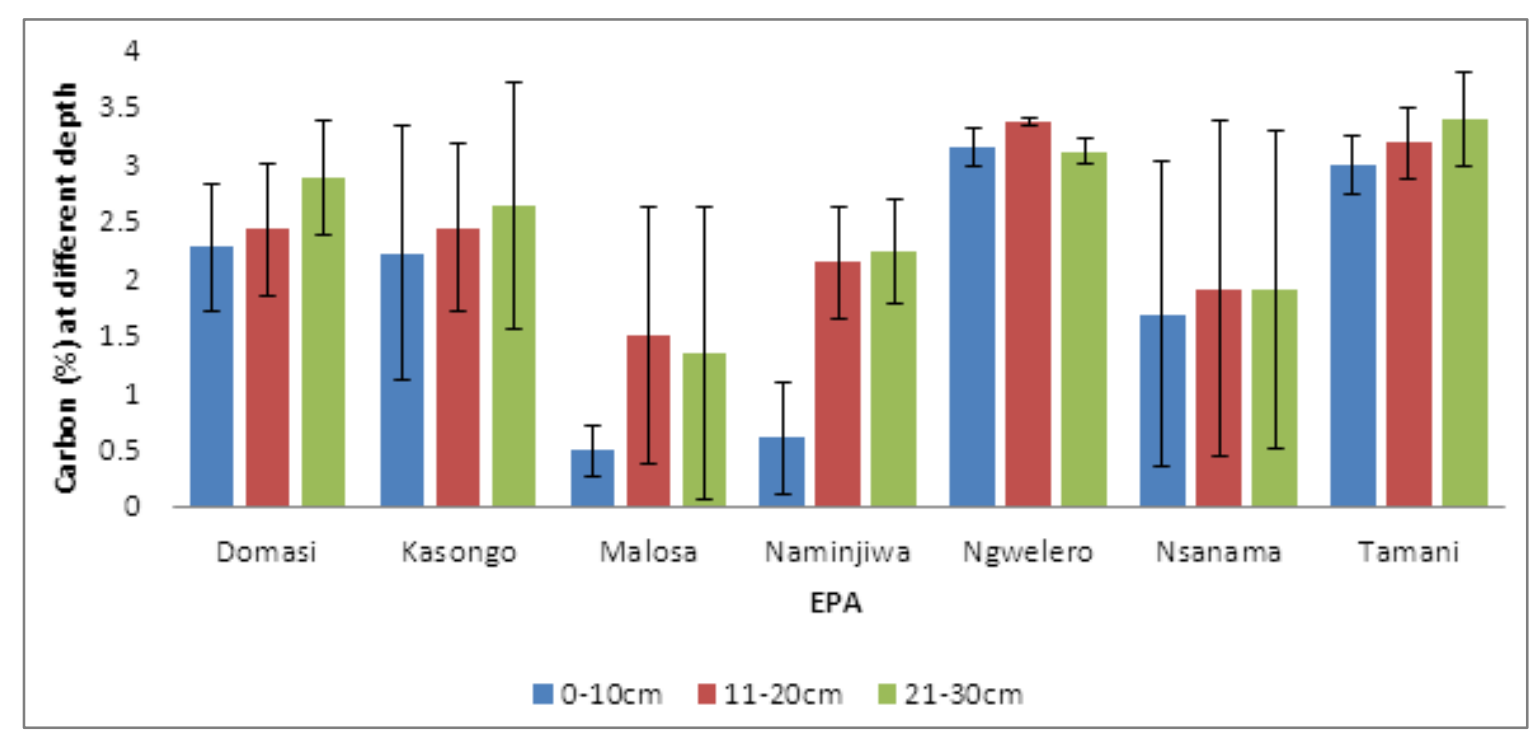

Figure 6. Available soil carbon at different soil depth (0 to $30 \mathrm{~cm})$ of the soil profile 


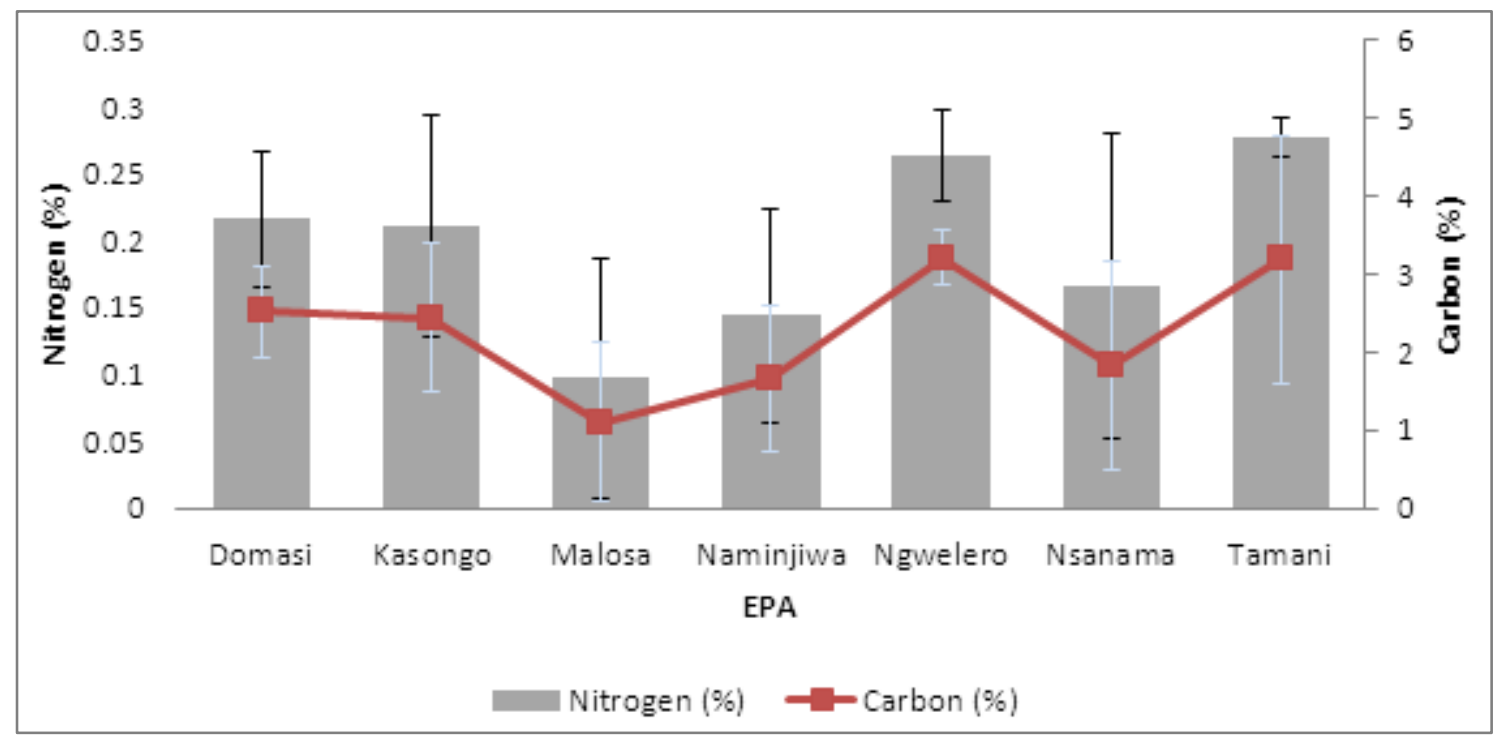

Figure 7. Relationship that exist between soil nitrogen and soil carbon in the study area

\subsubsection{Available Soil Nitrogen}

Baseline results show that Malosa EPA had the highest mean nitrogen percentage $(0.40 \%)$ and Ngwelero recorded the lowest nitrogen $(0.08 \%)$. The rest of the EPAs had mean nitrogen percentage below critical limit $(0.2 \%)$. The differences in nitrogen levels was attributed to differences in percentage organic matter available in the EPAs under study. It is not clear nonetheless, why Domasi EPA, which recorded highest mean SOM (3.32\%), did not constitute high mean percentage of nitrogen as expected. The inconsistency can be attributed to volatile nature of nitrogen that may be available in other different forms in varying conditions. The results generally showed that soils in the Lake Chilwa basin were nitrogen deficient. Soil nitrogen mean varied significantly $(\mathrm{P} \leq 0.05)$ across the EPAs under observation.

Results after 5years of CA implementation show that the overall mean nitrogen available is $0.2 \%$. Available nitrogen in the EPAs under study range between $0.11 \%$ and $0.31 \%$. Tamani has the highest available nitrogen at $0.31 \%$ while Malosa which had the highest available nitrogen during baseline, recorded the lowest nitrogen $(0.11 \%)$. Ngwelero EPA, which had the lowest available nitrogen before CA implementation, recorded $0.26 \%$ after 5years of CA practice. The recorded available nitrogen for Ngwelero is presently within acceptable limits. The results show significant difference $(\mathrm{P} \leq 0.05)$ across the EPA but no significant differences in soil depth from 0 to $30 \mathrm{~cm}$ $(\mathrm{P} \geq 0.05)$. In addition, the results are consistent with recorded SOM but also show direct proportional relationship that exist between soil nitrogen, soil carbon and soil organic matter in EPAs under study.

\subsubsection{Carbon: Nitrogen $(\mathrm{C}: \mathrm{N})$ Ratio}

Baseline results show that the recorded mean $\mathrm{C}: \mathrm{N}$ ratio ranged from 7.1 (Domasi EPA) to 11.7 (Ngwelero EPA).
Generally, the $\mathrm{C}: \mathrm{N}$ ratio was within the typical ranges in the basin. Statistically, C:N ratio varied significantly from one area to another $(\mathrm{P} \leq 0.05)$.

A follow-up review of $\mathrm{C}: \mathrm{N}$ ratio after 5 years of $\mathrm{CA}$ implementation indicate an overall mean ratio of $1: 10.58$ and ranged between 8.23 and 11.7. Domasi EPA maintained the mean ratio of 11.7 as was the case at baseline while Malosa recorded 8.23. The results for the $\mathrm{C}: \mathrm{N}$ ratio statistically show significant differences $(\mathrm{P} \leq 0.05)$ across EPAs but are not significantly different from 0 to $30 \mathrm{~cm}(\mathrm{P} \geq 0.05)$.

\subsubsection{Phosphorus Availability}

Baseline results showed that, except for Ngwelero EPA, mean phosphorus levels in all the sites were above critical limit $(\geq 20 \mathrm{ppm})$. Nsanama EPA had the highest mean phosphorus status (72.5 ppm) while Ngwelero EPA had the least mean phosphorus available $(7.89 \mathrm{ppm})$. Statistical test of the results show that there was significant difference $(\mathrm{P} \leq 0.05)$ of the means of phosphorus (ppm) in the soil across the EPAs under study.

5 years after CA implementation, the results show an overall mean of $16.87 \mathrm{ppm}$. Mean phosphorus levels ranged between 8.52 and 23.66ppm. Nsanama EPA (23.66ppm) recorded the highest phosphorus but a decline from $72.5 \mathrm{ppm}$ that was recorded at baseline. Ngwelero EPA (8.52 ppm) maintained its lowest status, but available phosphorus slightly increased from 7.89 ppm recorded at baseline after 5 years of CA implementation. The results did not show any significant variation $(\mathrm{P} \geq 0.05)$ from 0 to $30 \mathrm{~cm}$ but there was significant differences $(\mathrm{P} \leq 0.05)$ from one EPA to another.

\subsubsection{Available Potassium}

In this study, potassium $(\mathrm{K})$ is the only cation exchangeable base that was analyzed. Baseline results 
showed that Naminjiwa EPA had the highest mean potassium exchange capacity (0.21). Domasi EPA registered the least $(0.05)$. Statistical test of the results, however, showed that there were significant differences $(\mathrm{P} \leq 0.05)$ among the means of available potassium across the EPAs.

Review of available potassium 5years after CA implementation indicate an overall mean of 0.03 meq. Potassium mean generally declined and ranged from 0.02 to 0.04. Ngwelero EPA showed the highest mean of $0.04 \mathrm{meq}$ while Domasi EPA maintained its lowest status but this time declined from 0.05 to 0.02 meq. The results continued to show statistically no significant differences $(\mathrm{P} \geq 0.05)$ as we dig from 0 to $30 \mathrm{~cm}$ but statistically showed significant differences $(\mathrm{P} \leq 0.05)$ across the EPAs under study.

\subsection{Discussion}

Texture is one of the key physical properties of soil that influences the ease with which soils can be worked, amount of water and air it holds, rate at which water can enter and move through soil, organic matter content and $\mathrm{pH}$ buffering capacity [8]. As such, soil texture has an important role in soil nutrient management. Soil texture refers to the relative proportion of particles or the relative percentage by weight of the three soil separates viz; sand, silt and clay or simply refers to the size of soil particles. It is considered as a basic property of a soil because the proportion of each size group in a given soil (the texture) cannot be easily altered. Soil texture has an influence on soil bulk density.

Soil bulk density across the EPAs can generally be said to be good since it falls between $1.0 \mathrm{~g} / \mathrm{cm}^{3}$ and $2.0 \mathrm{~g} / \mathrm{cm}^{3}$. Largely, root penetration is well facilitated at bulk densities lower than $1.6 \mathrm{gcm}^{-3}$ [9]. Thus, as density decreases, pore space increases and the amount of air and water held in the soil also increases. The results (Figure 2) show that as soil organic matter level increases, soil bulk density decreases and vice versa. This is an indication that bulk density is influenced by soil organic matter such that low soil bulk density is desirable for crop and tree growth. The overall decrease in soil bulk density in this case is attributed to CA and this is good because low bulk density soils have greater water infiltration rates, which minimize runoff, improve water quality, and reduce storm water flow. It can be argued that soil improvement efforts such as mulching, crop associations and minimized soil disturbance under CA decreased soil bulk density over the years and increased soil pore spaces. Soils with granular structure (high percent organic matter) are higher in percent pore space regardless of the amount of sand or clay in the soil [9]. Subsequently, the soil contains relatively more air and water, and low bulk density can facilitate ease of root penetration. It can therefore be argued that good bulk density is a function of good soil whose condition can be further improved by CA practice. An ideal soil is usually described as being $50 \%$ solids and $50 \%$ pore space, with half the pore space filled with air and half with water [10]. This "ideal" soil would hold sufficient air and water to meet the needs of plants with enough pore space for easy root penetration, while the mineral soil particles would provide physical support and plant essential nutrients. Texture, structure, and organic matter combine to influence the amount of pore space. Continued practice of CA ensures attainment of such soil conditions achievable. Reference [11] argues that fine textured soils such as silt and clay have good soil structure and higher pore spaces. The soil bulk or dry density, which is the ratio of the mass of the solid phase of the soil (dried soil) to its total volume (solid and pore volumes together), depends on the mineral make up of soil and the degree of compaction. Bulk density is an important soil parameter in its own right as it reflects the soil's ability to function for structural support, water and solute movement, and soil aeration [9]. Bulk densities above thresholds (Table 1) indicate impaired function. Thus, the bulk densities of all textural classes in the Lake Chilwa basin are within ideal ranges for proper water infiltration, aeration and plant root growth and health. This implies that CA has had a positive influence on bulk density and in this case, soil bulk density cannot be one of the factors for poor crop production in the basin.

The effect of soil $\mathrm{pH}$ is great on the solubility of minerals or nutrients. Plants can use any of the fourteen (14) essential nutrients that are obtained from the soil only when a nutrient has dissolved in the soil solution. Most minerals and nutrients are more soluble or available in acid soils than in neutral or slightly alkaline soils $[12 ; 13]$. Soil power of hydrogen $(\mathrm{pH})$ or soil reaction is an indication of the acidity or alkalinity of soil. Soil $\mathrm{pH}$ is thus defined as the negative logarithm of the hydrogen ion concentration [9]. Soil $\mathrm{pH}$ therefore influences the nature and quantity of minerals or nutrients available in the soil for plant use and as such influences plant growth. Such being the case, it can be argued from the observed changes that CA practice had an influence in changing the status of soil $\mathrm{pH}$ whereby some soils that were initially recorded as near neutral or alkaline have now become slightly acidic.

In addition, soil $\mathrm{pH}$ can also influence plant growth by its effect on activity of beneficial microorganisms. Bacteria that decompose soil organic matter are hindered in strong acid soils and this condition prevents organic matter from breaking down, resulting in an accumulation of organic matter and the tie up of nutrients, particularly nitrogen, that is held in the organic matter $[9 ; 12]$. It is therefore not unusual that the study revealed an inverse relationship between soil $\mathrm{pH}$ status and available SOM.

Soil organic matter (SOM) represents an accumulation of partially decayed and partially synthesized plant and animal residues. CA can increase the ability of small-holder farmers to adapt to climate change by reducing vulnerability to drought and enriching the local natural resource base on which agriculture productivity depends [4]. It can then be argued that consistent CA practice in the Lake Chilwa basin can increase the input of fresh organic matter, controlling of soil organic material losses through 
soil erosion, and reducing the rate of soil organic material mineralization. The organic matter content of soils is small varying from $2 \%$ to $6 \%$ by weight in typical well-drained mineral soils. In its broadest sense, soil organic matter comprises all living soil organisms and all the remains of previous living organisms in their various degrees of decomposition that CA provides to the soil. Nutrient supply, water holding capacity, soil structure aggregation and erosion control are largely influenced by SOM [12]. Soil organic matter, hence, plays a key role in soil health through biological, physical and chemical functions. Chemically, SOM largely influence the ability of the soil to hold cations which are measured by the cation exchange capacity (CEC). Negatively charged sites of SOM typically have twice the charge of clay minerals and even low levels of SOM can make a significant contribution to the CEC [13; 11]. Some of the compounds within SOM are taken up directly into the plant through mycorrhizal associations; and active SOM ensures that the soil remains active biologically $[9 ; 13]$. In crop nutrition, SOM contribute to the presence of functional groups such as amino, hydroxyl and carboxyl compounds which give rise to high CEC and the ability to complex with clays and contribute to soil structure. Thus, SOM act as ion exchangers and as a result contribute to plant nutrition to a certain extent. In addition, SOM can hold and buffer trace elements by chelation when they act as scrubber to avoid toxic level of trace elements.

The negligible decline in SOM in the two EPAs in this study is attributed to SOM loss through leaching during the 2015 rainfall season caused by water logging conditions that the CA fields experienced. Considering the amount of partially decayed and partially synthesized plant residues that got into the CA fields considerable gains in SOM are expected under consistent CA practice. Reference [14; 15] reports higher yields through better water use and improved soil quality; the latter caused by an increase in soil organic carbon and nitrogen and a slight $\mathrm{pH}$ decline in the seed zone. This is evidence enough that despite ecological disruptions that come with climate change, $\mathrm{CA}$ is capable of restoring agricultural soils and make them productive again.

Soil carbon is supposed to be more concentrated in the 0 $-10 \mathrm{~cm}$ range but this was not the case in this study. It is within the soil top layer where there are more organic material and more microbial activities taking place [9]. Increasing amounts of soil carbon can increase the reservoir of available plant nutrients, improve water - holding capacity, increase CEC and stimulate soil biological activity. However, with climate change and variability bringing extreme weather events such as drought in the basin, the likelihood of losing soil carbon especially in the top soil is potentially high. Increasing temperatures would increase oxidation of organic soil carbon, leading to further reduction of carbon levels in soils [16]. These changes reflect themselves in poor soil fertility, loss of soil biota and water stress. Soil organic carbon as the main constituent of SOM is formed by the biological, chemical and physical decay of organic materials that enter the soil system from sources above ground (e.g. leaf fall, crop residues, animal wastes and remains) or below ground (e.g. roots and soil biota). Each fraction of soil carbon has different functions, most of these are due to the relative stability and biological availability of each fraction provide energy to soil biological processes which are important for soil structure, energy for biological processes and provision of nutrients.

CA enhances carbon inputs to the soil. Reference [17] argues that additions of nitrogen fertilizer alone do not increase soil carbon or nitrogen stock especially in sandy soils. In the absence of crop residue returns, inorganic fertilizers alone do not provide carbon sources and results in losses of nitrogen fertilizers through leaching and denitrification.

Nitrogen is the nutrient element most often deficient for crop production in Malawi soils and any gains result in substantial economic return for farmers. However, when nitrogen inputs to the soil system exceed crop needs, there is a possibility that excessive amounts of nitrate $\left(\mathrm{NO}_{3}{ }^{-}\right)$may enter either ground or surface water. Nitrogen exists in the soil system in many forms and transforms very easily from one form to another. The route that nitrogen flows in and out of the soil system is collectively called the "nitrogen cycle" and is biologically influenced [9]. Biological processes, are in turn influenced by prevailing climatic conditions along with the physical and chemical properties of a particular soil. It is thus likely that Malosa EPA lost such an amount of available soil nitrogen due to its volatile nature or heavy leaching which was influenced by flooding events of 2015 rainfall season.

Soils in the basin have generally improved over the past 5 years in as far as $\mathrm{C}: \mathrm{N}$ ratio is concerned (ranging between 8.23 and 11.7 from a range of 7.1 and 11.7). Reference [9] reports that $\mathrm{C}: \mathrm{N}$ ratio in agro-ecosystems normally ranges from 9 to 14 and high $\mathrm{C}: \mathrm{N}$ ratio leads in immobilization. This implies that soils in the Lake Chilwa basin are less likely to have problems of slow rates of decay or immobilization. This makes CA more appropriate in the basin as mulch used in soil cover can decay easily and form part of soil in succeeding years without chemical impediments, unlike in areas where $\mathrm{C}: \mathrm{N}$ ratio is too high.

The persistent low phosphorus availability for Ngwelero EPA could be attributed to the type and low amounts of clay or iron oxide content considering that the continued NPK investments in the basin's soils should have by now raised Phosphorus level to within critical limit (( $\geq 20 \mathrm{ppm})$. Current results after CA practice show that only Nsanama and Domasi EPAs had phosphorus above critical limits at $23.66 \mathrm{ppm}$ and $21.35 \mathrm{ppm}$ respectively. The observed decline in phosphorus observed after 5 years of CA practice can be attributed to leaching especially during the 2015 rainfall season when the basin received extreme rains that led to waterlogging conditions and subsequent flooding. The decline of phosphorus status in the soil imply that the rate of energy transfer for crops grown in these areas is no longer good. The soil condition has been worsened by the 
available soil $\mathrm{pH}$ levels $(<6.5)$ in all sites under study because there is a possibility that the little available soil phosphorus may not be readily used by plants due to fixation by aluminum ions under acid conditions [11]. This partially explains why continued application of NPK fertilizers are not reflected in the recorded levels of phosphorus in the basin. According to [9], the total phosphorus content of most surface soils is low, averaging only $0.6 \%$ phosphorus. This compares to an average soil content of $0.14 \%$ nitrogen and $0.83 \%$ potassium. The potassium status does not apply to the Lake Chilwa basin in this case considering the low levels of potassium recorded in the areas under study.

The available potassium observed across the EPAs at both baseline and after 5 years of $\mathrm{CA}$ implementation fall below threshold levels $(0.5 \mathrm{meq})$. Low levels of potassium in most EPAs in the basin can be attributed to dominance of sand apart from leaching through water logging conditions of 2015 rainfall season. Sandy soils have the lowest potassium content while clay and alluvial soils have the highest [9]. Potassium in the soil solution is subject to leaching and it is more readily leached than phosphorus but less so than nitrate nitrogen. Potassium that is dissolved in soil water (water-soluble) and that held on the exchange sites on clay particles (exchangeable $\mathrm{K}$ ) is considered readily available for plant growth. Nonetheless, clay soils can even become depleted of potassium when considerable quantities are removed in farm produce. In this study, potassium that is held on the exchange sites is what was measured during baseline and after 5years of CA practice. Potassium is supposed to be quite abundant in soils, typically ranging from 0.5 to 4.0 meq [9] but this was not the case in this study. The study may have recorded less $\mathrm{K}$ because only a small part of available soil $\mathrm{K}$ is present in water-soluble and exchangeable forms that is readily available for plant uptake. This is usually less than $1 \mathrm{meq} \%$ of the total. Plants readily absorb the $\mathrm{K}$ dissolved in the soil water and as soon as the $\mathrm{K}$ concentration in soil water drops, more is released into the solution from the $\mathrm{K}$ attached to the clay minerals. Thus, $\mathrm{K}$ attached to the exchange sites on the clay minerals is more readily available for plant growth than the $\mathrm{K}$ trapped between the layers of the clay minerals. Higher soil moisture usually means greater availability of K and this means that increasing soil moisture increases movement of $\mathrm{K}$ to plant roots and enhances availability. In this case, the findings of $\mathrm{K}$ levels for this study reflect the dry condition of the soil samples collected for analysis.

\section{Conclusions}

Contrary to what was expected, a review of soil status after some years of CA practice has not shown improvement in all soil properties under observation. The study has however revealed some improvements in the observed physical and some soil chemical properties but also a decline in other soil chemical properties across the 7
EPAs within the Lake Chilwa basin. Physically, improvements have been observed in bulk density through overall reduction in soil bulk density mean for all the seven (7) EPAs after 5years of CA practice. Chemically, soil pH generally dropped in all the 7 EPAs after 5 years of CA implementation such that the soils can be said to be slightly acidic and still tolerable for agricultural production. It was observed that there is an increase in SOM status in all the EPAs under study except Domasi and Naminjiwa EPAs which recorded slight declines. It was further observed that the gains and losses in SOM did not correspondingly translate into increases and decreases respectively of nitrogen in the EPAs under observation. Nonetheless, Nsanama, Tamani and Ngwelero EPAs showed an increase in nitrogen and correspondingly had SOM gains over the years; Kasongo and Malosa EPAs recorded a decline in nitrogen status even though they had made gains in SOM. Soil carbon status showed to be increasing in Malosa, Kasongo, Nsanama, Tamani and Ngwelero EPAs as expected, considering that carbon is a key ingredient of SOM. Correspondingly, soil carbon decreased in Domasi and Naminjiwa EPAs where SOM was observed to be declining. Results on soil phosphorus status in all the EPAs under study show a decline except in Ngwelero EPA where an increase was recorded after 5 years of CA implementation. Similarly, there was a decline in potassium status in all the EPAs under study except in Malosa where it remained static, 5 years after CA implementation. It is feared that the flooding events in the fifth year of CA implementation may have had an effect on the chemical status of the soil in the EPAs under study due to the resultant nutrient leaching. It is thus expected that the soil may recover under continued $\mathrm{CA}$ practice as long as extreme rainfall do not lead to field water logging conditions.

Nonetheless, CA has shown that it has the potential and capacity to increases the input of fresh organic matter, controlling of soil organic material losses through soil erosion, and reducing the rate of soil organic material mineralization. CA would also allow farmers to make more use of nutrients from crop residues and agroforestry for soil amelioration. This means fields can be cultivated for a longer period of time with a sustained stable productivity thereby potentially reducing the need for land conversion. Even though 5 years of CA practice has failed to show significant gains in the soil chemical properties apparently due to heavy nutrient leaching that was experienced when the basin received extreme rains, the study has shown that CA has the potential to improve soil status as it has been observed in some soil properties of interest. Such being the case, CA should still be considered a potent adaptation measure to climate change as it increases farmers' resilience especially during drought by increasing soil water- use efficiency for stable yields. Such being the case, practitioners should not only stress on improved crop yields from CA, but also provide evidence of soil productivity under CA. 


\section{Acknowledgements}

Both the soil baseline survey and subsequent soil study after 5 years of Conservation Agriculture practice in the Lake Chilwa Basin would not be successful had it not been for the valuable support rendered by different individuals and institutions. For this reason, we recognize the contributions by Mr. Steve Makawa of Forestry Research Institute of Malawi (FRIM) during data collection and laboratory analysis of soil samples. We also acknowledge LCBCCAP for the financial support with which this study was made possible. All individuals and institutions, too numerous to mention, who directly or indirectly offered any support are profoundly recognized.

\section{REFERENCES}

[1] Mongi, H.O. and Huxley, P.A. (eds.). (1979). Soils Research in Agroforestry. ICRAF. Nairobi.

[2] Mucavele, F.G. (2009). True Contribution of Agriculture to Economic Growth and Poverty Reduction: Malawi, Mozambique and Zambia Synthesis Report. Universidade Eduardo Mondlane, Mozambique.

[3] Saka, A. R. (2002). Evaluating soil physical and chemical characteristics for describing nutrient leaching in agricultural soils. Department of agriculture research services, Ministry of agriculture. Malawi.

[4] Food and Agriculture Organization (FAO). (2008). What is Conservation Agriculture. In: Conservation Agriculture Website of FAO, www.org/ag/ca/la.html.

[5] Mwafongo, W.M.K. (1998). A Study of Lake Chilwa Wetland as a Potential Ramsar Site: Physical, Socio-Economic, and Cultural Aspects. In: Van Zegeren and Munyenyembe, M.P. (ed.) A report of the 1996 Ramsar site study. Department of Biology, Chancellor College, University of Malawi, Zomba.

[6] Mhango, D.H.Z., Kazgeba-Mfune, J. and Mwafongo, W.M.K. (1992). The Ecology, Biological Diversity and Current Uses of Lake Chilwa. Paper presented at Malawi's Wetlands
Seminar, IUCN-ROSA, 11 - 13 November, Liwonde, Machinga.

[7] Anderson S.E. and Ingram J.S.I. (1989). Tropical Soil Biology and Fertility: A Handbook of Methods. p. 171. C.A.B. International, Aberystwyth.

[8] Brady, N. C. (1984). The nature and properties of soil. Macmillan Book Co., New York.

[9] Brady, N. C. and Weil R. R. (2002). The Nature and Properties of Soils.13th ed. Pearson education, Inc., New Jersey. http://www.soilsurvey.org/tutorial/page10.asp. Retrieved on $3 / 12 / 2012$

[10] Muya, E. M., Obanyi, S., Ngutu, M., Sijali, I.V., Okoti, M., Maingi, P.M., and Bulle, H. (2011). The physical and chemical characteristics of soils of Northern Kenya Aridlands: Opportunity for sustainable agricultural production. Journal of Soil Science and Environmental Management Vol. 2(1), pp. 1-8.

[11] [11]Wild, A. (2003). Soils, Land and Food. Managing the land during the twenty-first century. Cambridge University Press. UK.

[12] Sposito, G. (1989). The Chemistry of Soils. Oxford University Press. NewYork.

[13] Mrabet, R. (2003). No - tillage farming: Renewing harmony between soils and crops in semi-arid Morocco. Embrapa Solos. 40: $1-4$.

[14] Mrabet, R., El Brahli, A., Anibat, I. and Bessam, F. (2000). No-tillage technology: Research review of impacts on soil quality and wheat production in semiarid Morocco. In: Cantero-Martínez C. and Gabiña D. (eds.). Mediterranean rainfed agriculture: Strategies for sustainability. Zaragoza: CIHEAM, 2004. p. 133-138 (Options Méditerranéennes: Série A. Séminaires Méditerranéens; n. 60).

[15] FAO. (2011). The State of Food and Agriculture. Women in Agriculture. Losing the Gender Gap for Development. Rome: Food and Agriculture Organization of the United Nations.

[16] Pieri, C. (1987). Management of acid tropical soil in Africa, pp. 41-61. In: Process of Management of Acid Tropical Soils for Sustainable Agriculture. IBSRAM Inaugural Workshop. Yurimaguas, Peru, and Brasilia, Brazil. 24 Apr. - 3 May 1985. Int. Board for Soil Res. And Manage, Bangkok, Thailand. 